\title{
Phyllanthus reticulatus Prevents Ethanol-Induced Gastric Ulcer via Downregulation of IL-8 and TNF- $\alpha$ Levels
}

\author{
Hafsa Izhar, ${ }^{1}$ Arham Shabbir $\mathbb{D}^{2},{ }^{2}$ Muhammad Shahzad, ${ }^{3}$ Aisha Mobashar, ${ }^{1}$ \\ and Syed Shoaib Ahmed ${ }^{4}$ \\ ${ }^{1}$ Department of Pharmacology, Faculty of Pharmacy, The University of Lahore, Lahore Campus, Lahore, Pakistan \\ ${ }^{2}$ Institute of Pharmacy, Faculty of Pharmaceutical and Allied Health Sciences, Lahore College for Women University, \\ Jail Road, Lahore, Pakistan \\ ${ }^{3}$ Department of Pharmacology, University of Health Sciences, Lahore, Punjab, Pakistan \\ ${ }^{4}$ Centre for Research in Molecular Medicine, The University of Lahore, Lahore Campus, Lahore, Pakistan
}

Correspondence should be addressed to Arham Shabbir; charham007@hotmail.com

Received 12 May 2021; Revised 11 September 2021; Accepted 14 September 2021; Published 25 September 2021

Academic Editor: Slim Smaoui

Copyright ( $\odot 2021$ Hafsa Izhar et al. This is an open access article distributed under the Creative Commons Attribution License, which permits unrestricted use, distribution, and reproduction in any medium, provided the original work is properly cited.

\begin{abstract}
The current study aimed to determine the protective effect of $P$. reticulatus on ethanol-induced gastric ulcer. For this purpose, thirty-six Sprague-Dawley rats were divided into six groups. The first group served as normal control, while, in other five groups, absolute ethanol was used to induce gastric ulcer. Group II served as a diseased group, while groups III, IV, and V were treated with methanol extract, ethyl acetate fraction, and $n$-hexane fraction, respectively, in a dose of $400 \mathrm{mg} / \mathrm{kg}$ bodyweight. Group VI was given omeprazole in a dose $20 \mathrm{mg} / \mathrm{kg}$ bodyweight. The stomachs were removed, ulcer score was evaluated, and histopathological examination of gastric lumen was conducted. Total acidity and $\mathrm{pH}$ values were determined in gastric juice. TNF- $\alpha$ and IL- 8 mRNA expressions levels were determined using the reverse transcription real-time PCR method. The data indicated that $P$. reticulatus protected against gastric ulcer, which was evident by attenuation of ulcer score. The pretreatment with $P$. reticulatus raised the gastric $\mathrm{pH}$ and improved all evaluated histopathological parameters such as ulcer score, erosion score, hemorrhage score, fibrinoid necrosis score, inflammatory infiltrate score, and edema score. P. reticulatus significantly reduced mRNA expression levels of TNF- $\alpha$ and IL-8. In conclusion, P. reticulatus possess antiulcer property which might be attributed to downregulation of TNF- $\alpha$ and IL-8 expression levels.
\end{abstract}

\section{Introduction}

The pathophysiology of peptic ulcers is mainly focused between aggressive (chloride corrosive effects and pepsin) and defensive elements (body fluids, bicarbonate secretions, prostaglandins, sulfhydryl compounds, polyamines, nitric oxide, and dopamine) [1]. Abdominal pain, epigastric tenderness, nausea, ample vomiting, and distention are common signs and symptoms [2]. Microscopic appearance determines the base of the ulcer in 4 zones, i.e., inflammatory exudate, fibrinoid necrosis, tissue granulation, and fibrous tissue during the active stage. The fibrous base of the ulcer may contain vessels with thickened wall or with thrombosis [3].

Therapeutic management and treatment of peptic ulcer includes several classes of drugs, i.e., (PPI's) proton pump inhibitors, histamine receptor blockers, mucosal blockers, and prostaglandin analogs. However, development of tolerance and side effects has led to doubts about the efficacy of these drugs, suggesting the need to develop new drugs against ulcers [4]. Plant-derived medicinal treatment is common and extends to traditional and modern medicinal practice. As stated by the World Health Organization, more than $80 \%$ of community in developing countries is largely dependent on herbal medicine [5].

Phyllanthus reticulatus Poir. (family: Euphorbiaceae), commonly known as pancoli or carinelli, is a giant hairless or pubescent shrub with smooth or lenticular late branches, 8-10 feet in height. Its leaves are oval to elliptical or obovate, and the organic product is purple dark berries [6]. The plant is known to have analgesic, anti-inflammatory, cholesterol 
lowering, cytotoxic, immunomodulatory, antidiabetic, antimalarial, antibacterial, and hepatoprotective effects [7]. In the traditional system of medicine, the plant is used as a remedy of gastrointestinal disorders [8]. The ethanolinduced gastric ulcer model is widely used to evaluate the gastric cytoprotective effect of plant extract against ingested irritants. The current study aimed to evaluate the immunomodulatory activities of $P$. reticulatus against ingested irritants using ethanol-induced gastric ulcer model in rats.

\section{Methodology}

2.1. Plant Collection. Phyllanthus reticulatus was collected from the botanical garden of Government College University, Lahore, and the specimen was confirmed by Dr. Zaheer-u-din at the Department of Botany, Government College University, Lahore. A specimen voucher was deposited in the herbarium of the University (GC.Herb.Bot.3474).

\subsection{Preparation of the Plant Extract and Fractionation.} The collected plant leaves were carefully washed to remove contaminants. The leaves were dried in the air under shadow for 15 days and powdered using the grinder. The ground powder $(500 \mathrm{~g})$ was immersed in 2 liters of methanol using an airtight glass bottle. The bottle was stored at room temperature for 7 days with recurrent shaking. The material was first filtered with muslin cloth and then by using filter paper (Whatman number 1).

The obtained filtrate was evaporated by using the rotary evaporator under low pressure to obtain semisolid thick extract. Then, the crude methanolic extract was dissolved in $200 \mathrm{ml}$ distilled water.

The obtained solution was placed for liquid-liquid extraction, by using $n$-hexane and separating funnel. The $n$ hexane fraction was collected, and the excessive solvent was evaporated using the rotary evaporator under low pressure. After separating the $n$-hexane layer, the aqueous layer was again subjected to fractionation by using ethyl acetate solvent [9].

2.3. Experimental Animals. Thirty-six Sprague-Dawley rats, 150-250 grams, of either sex, were divided into six groups each having 6 rats. Animals were maintained in the animal house of the University of Lahore at controlled room temperature $\left(26 \pm 2^{\circ} \mathrm{C}\right)$ and humidity (40-60\%) conditions. Dark and light cycles (12 hours) were also ensured. Rats were fed on standard diet and water ad libitum [10]. The experiments were approved by Institutional Research Ethics Committee, the University of Lahore (IREC-2018-52).

\subsection{Experimental Design}

2.4.1. Group I (Naive). Normal saline was given to rats in this group.
2.4.2. Group II (Vehicle Control). Ethanol was given orally to rats at a dose of $5 \mathrm{ml} / \mathrm{kg}$ b.w. in a single dose by the gavage method [11].

2.4.3. Group III (Meth-Treated). Methanolic extract of P. reticulatus was given at a dose of $400 \mathrm{mg} / \mathrm{kg}$ b.w., p.o. [12]. Then, after $1 \mathrm{~h}$ of extract administration, ethanol (100\%) was given in a single oral dose $(5 \mathrm{ml} / \mathrm{kg}$ b.w.).

2.4.4. Group IV (NH-Treated). Rats were pretreated with $n$ hexane fraction of $P$. reticulatus at a dose of $400 \mathrm{mg} / \mathrm{kg}$ b.w., p.o. [12]. Then, after $1 \mathrm{~h}$ of pretreatment, absolute ethanol was administered in a single oral dose $(5 \mathrm{ml} / \mathrm{kg}$ b.w.).

2.4.5. Group $V$ (EA-Treated). This group was pretreated with ethyl acetate fraction of $P$. reticulatus at a dose of $400 \mathrm{mg} / \mathrm{kg}$ b.w., p.o. [12]. Absolute ethanol was administered $(5 \mathrm{ml} / \mathrm{kg}$ b.w.) after $1 \mathrm{~h}$ of pretreatment with ethyl acetate fraction.

2.4.6. Group VI (OM-Treated). Omeprazole was given to rats in this group at a dose of $20 \mathrm{mg} / \mathrm{kg}$ b.w., p.o. [13]. Subsequently, absolute ethanol was administered $(5 \mathrm{ml} / \mathrm{kg}$ b.w.) after $1 \mathrm{~h}$ of pretreatment.

2.5. Pylorus Ligature and Removal of Gastric Tissue. Rats were sacrificed after two hours of ethanol administration [14]. The stomachs were first ligated with thread from both ends. The stomachs were punctured through sterilized needle, and gastric juice was collected within Eppendorf tubes [15]. Then, stomachs were opened along greater curvature for two parameters. One sample was immersed in $10 \%$ buffered formalin for histopathological analysis and kept at room temperature. Another sample was immersed in $100 \mathrm{ml}$ TRIzol reagent for RT-PCR analysis and kept at $-80{ }^{\circ} \mathrm{C}$.

2.6. Ulcer Score. Morphological features of the gastric ulcer such as redness, erythema, and hemorrhage were determined. Ulcer score was measured by giving 0 to normal mucosa/no ulcer, 1 to mucosal lesion limited to superficial layer/superficial ulcer, 2 to mucosal lesion penetrated to deep layer/deep ulcer, and 3 to mucosal damage with a hole/ perforation [16].

2.7. Determination of Gastric Acidity and $p H$. The stomachs were removed, and gastric contents were collected to measure $\mathrm{pH}$ values. The gastric contents were centrifuged at $1200 \mathrm{rpm}$ for 10 minutes, and $\mathrm{pH}$ values were determined. Total acid in gastric juice was evaluated in supernatant by titration as $\mathrm{pH} 7.0$ with $0.01 \mathrm{~N} \mathrm{NaOH}$ solution and phenolphthalein as an indicator [17].

2.8. Histopathological Assessment. For histopathological examinations, stomach tissues were immersed in $10 \%$ buffered formalin, fixed in formalin solution. After fixation, the stomachs were cut open longitudinally along greater 
curvature, and pathological changes in the stomach lumen were observed. $2-3 \mathrm{~mm}$ thick sections from representative areas were taken and processed to prepare paraffin blocks. Section was cut at $5 \mu \mathrm{m}$ of thickness and stained with hematoxylin and eosin [18]. Sections were then evaluated microscopically for histological changes including erosions, edema, hemorrhage, fibrinoid necrosis, and inflammatory cell infiltration.

\subsection{Evaluation of $m R N A$ Expression Levels of IL-8 and TNF- $\alpha$ using qRT-PCR Analysis}

2.9.1. Extraction of RNA and Synthesis of Complementary DNA. Briefly, gastric tissues were mixed with TRIzol reagent and homogenized. $150 \mu \mathrm{L}$ of chloroform were added, contents were centrifuged, and the top transparent layer (aqueous phase) containing RNA was separated. Then, isopropanol of equal proportion was added for precipitation of RNA. The RNA pellets were washed with $1 \mathrm{ml}$ of $75 \%$ ethanol. RNase free water $(20 \mu \mathrm{L})$ was added to solubilize RNA pellet. The quantity of RNA was measured using the nanodrop spectrophotometer.

cDNA was synthesized by reverse transcription using the cDNA synthesis kit (Thermo scientific America). $1000 \mathrm{ng}$ of RNA from each sample was mixed with oligo dt primer $(10 \mu \mathrm{M})$, nuclease free water, centrifuged, placed in the thermal cycler for heating for $5 \mathrm{~min}$ at $70^{\circ} \mathrm{C}$, and immediately chilled afterwards. Further components of the kit were added, i.e., $4 \mu \mathrm{L}$ of $5 \mathrm{X}$ reaction buffer, $0.5 \mu \mathrm{L}$ of RNase inhibitor $(20 \mathrm{U} / \mu \mathrm{L}), 2 \mu \mathrm{L}$ of dNTP $\operatorname{mix}(10 \mathrm{mM})$, and $0.5 \mu \mathrm{L}$ of MMuLV enzyme $(200 \mathrm{U} / \mu \mathrm{L})$. All PCR tubes were placed in the thermal cycler (BioRad, USA) for $60 \mathrm{~min}$ at $40^{\circ} \mathrm{C}$ [19].

2.10. Real-Time Polymerase Chain Reaction ( $q P C R)$. For amplification, $2 \mu \mathrm{L}$ of cDNA was mixed with $1.5 \mu \mathrm{L}$ of reverse and forward primer, each $(10 \mu \mathrm{M}), 6 \mu \mathrm{L}$ of PCR Master Mix containing SYBR green dye, and $2 \mu \mathrm{L}$ of nuclease free water q.s. to $12 \mu \mathrm{l}$. Thermal cycler was programed for denaturation cycle at $95^{\circ} \mathrm{C}$ for $10 \mathrm{~s}$, annealing at $60^{\circ} \mathrm{C}$ for $30 \mathrm{~s}$ (cycles $=45$ ), and extension at $72^{\circ} \mathrm{C}$ for 30 s. Gene expression levels were recorded as threshold cycle $(\mathrm{Ct})$ values.

2.11. Statistical Analysis. Data were analyzed using GraphPad Prism v.6 software and presented in the form of mean \pm standard deviation. To analyze quantitative variables, one-way ANOVA was used. To compare all groups with each other, the post hoc Tukey's test was used.

\section{Results}

3.1. Histopathological Studies. Pretreatment with plant extracts and omeprazole attenuated ulcer score, erosion score, hemorrhage erosion, fibrinoid score, inflammatory infiltrate score, and edema score (Figure 1; Table 1).

3.2. Measurement of Gastric $p H$. Gastric contents of each rat were collected and centrifuged at $3000 \mathrm{rpm}$ for $10 \mathrm{~min}$.
Graphical representation shows the $\mathrm{pH}$ changes in the diseased group and treated groups after ulcer induction with ethanol. Significantly lower $\mathrm{pH}$ was observed in the vehicle control group rats as compared with the naive group $(5.400 \pm 0.3521$ vs. $6.950 \pm 0.4324)$. The $\mathrm{pH}$ values were found significantly $(P<0.001)$ increased in the Meth-treated group (7.350 \pm 0.2881$)$, EA-treated group (7.383 \pm 0.1941$)$, $\mathrm{NH}$-treated group $(7.300 \pm 0.1789)$, and OM-treated group (7.400 \pm 0.1897 ) (Figure 2).

3.3. Measurement of Total Gastric Acidity. Total gastric acidity was measured from the gastric contents of normal, diseased, and treated groups of rats. It was found that the total acidity was substantially decreased $(P<0.001)$ in OMtreated $(57.2 \pm 1.82)$, NH-treated $(61.3 \pm 2.42)$, EA-treated $(61.8 \pm 1.62)$, and Meth-treated groups $(62.3 \pm 1.61)$ in comparison to the vehicle control group $(76.3 \pm 2.79)$ (Figure 3).

3.4. Effects of $P$. reticulatus on Ulcer Score. Results showed elevated $(P<0.001)$ ulcer score in the vehicle control group $(2.0 \pm 0.6325)$ as compared to naive. Meth-treated $(0.2500 \pm 0.4183 ; \quad P<0.001), \quad$ EA-treated $(0.6667 \pm 0.8165$; $P<0.01)$, and NH-treated $(0.3333 \pm 0.5164 ; \quad P<0.001)$ groups showed reduction in ulcer score as compared to the vehicle control group. Similarly, omeprazole treatment $(0.3333 \pm 0.4082 ; P<0.001)$ also caused suppression of ulcer score as compared to the vehicle control group (Figure 4).

3.5. Effects of P. reticulatus on IL-8 mRNA Expression Levels. Results showed elevated $(P<0.001)$ mRNA expression levels of IL- 8 in the vehicle control group as compared to naive $(2.733 \pm 0.8029$ vs. $1 \pm 0.4102)$. Meth-treated $(1.308 \pm 0.7010$; $P<0.01)$, EA-treated $(1.172 \pm 0.4001 ; P<0.01)$, and $\mathrm{NH}-$ treated $(1.706 \pm 0.4913 ; P<0.05)$ groups showed significant downregulation in IL-8 levels as compared to the diseased group. Similarly, omeprazole treatment $(1.369 \pm 0.4177$; $P<0.01)$ also caused downregulation of IL-8 levels as compared to the vehicle control group (Figure 5(a)).

3.6. Effects of P. reticulatus on TNF- $\alpha$ mRNA Expression Levels. The data demonstrated upregulation $(P<0.01)$ in the levels of TNF- $\alpha$ in the vehicle control group as compared to naive $(2.291 \pm 0.6945$ vs. $1 \pm 0.5749)$. Meth-treated $(1.237 \pm$ $0.4829)$, EA-treated $(1.409 \pm 0.4912)$, and NH-treated $(1.277 \pm 0.5750)$ groups showed reduction $(P<0.05)$ in the mRNA expression levels of TNF- $\alpha$. Similarly, omeprazole treatment also downregulated TNF- $\alpha$ levels $(P<0.05)$ compared to the vehicle control group $(1.171 \pm 0.1882)$ (Figure 5(b)).

\section{Discussion}

Gastrointestinal ulcer is a disease that mainly occurs in the inner layer of the stomach lining or near the duodenum [20]. Gastric ulcer is one of the most common disorders, and a significant number of people are affected with this disease 


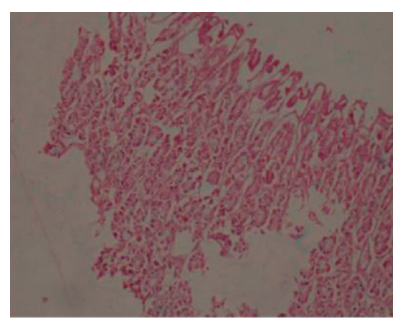

(a)

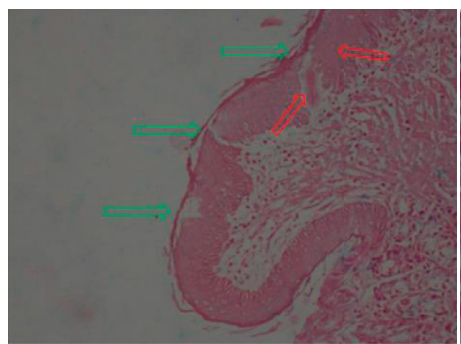

(d)

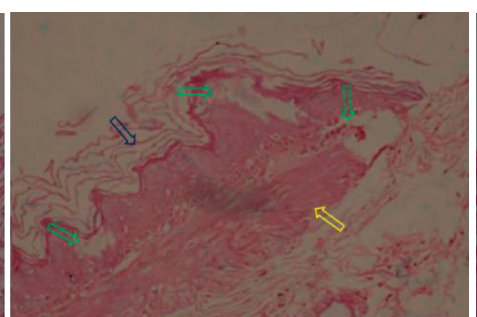

(b)

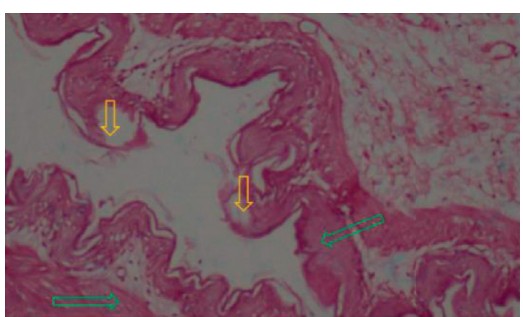

(c)



(e)

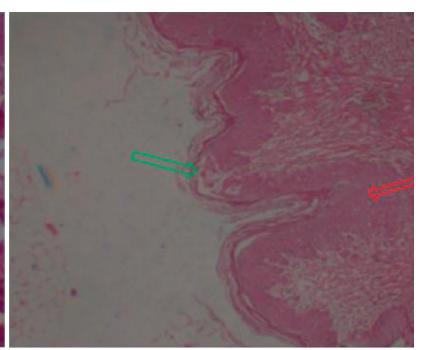

(f)

FIgURE 1: Gastric mucosa of animal from the naive control group showing normal architecture and structure. Mucosal glands showing normal ductal structure (a). Gastric mucosa of rats from the vehicle control group showing infiltration of inflammatory cells, erosions, and ulcer (green), sloughing of epithelial cells (blue), and also extensive fibrinoid necrotic areas with edematous transudate (yellow) (b). Gastric mucosa of rats from the Meth-treated group showing mild inflammatory infiltrate score and edematous mucosa (green). It shows no hemorrhage. Mild epithelial erosion is visible (yellow). Extensive fibronecrotic change was present (c). Gastric mucosa of rat from the NHtreated group showing no hemorrhage score. It shows mild fibrinous necrosis and edema (red). It shows multifocal sloughing of epithelial cells and disarray of the epithelial lining (green) (d). Gastric mucosa of animals from the EA-treated group showing no inflammatory cells, no hemorrhage, and ulcer. High columnar epithelia and normal architecture of mucosal glands is also detected (green) (e). Gastric mucosa of rat from the OM-treated group showing mild erosion (green) and no hemorrhage. It shows edematous mucosa (red) and no inflammatory infiltrate score (f).

around the world. The development of gastric ulcers is a complex and multifactorial pathological condition that affects a balance between aggressive and preventive factors present in the gastric mucosa [21]. Increased incidence of gastric ulcers is associated with aggressive factors against the gastric mucosa such as ethanol exposure, stress, smoking, nutritional deficiencies, hereditary predisposition, infection by Helicobacter pylori, and frequent ingestion of nonsteroidal anti-inflammatory drugs [22]. Major key factor causing gastric ulcer is the presence of high gastric acidity which can potentiate the action of aggressive agents within stomach mucosa [23]. Pathogenesis of gastric ulcer involves infiltration of inflammatory cell with poly morpho nuclear (PMN) neutrophils, lymphocytes, and eosinophils [24].

Medicinal treatment derived by plants is common and extends to traditional and modern medicinal practice. Phyllanthus reticulatus has been used in traditional Asian medicine for the treatment of diseases such as inflammation, diabetes, and microbial infections and as analgesic and hepatoprotective [25]. In the current study, we used the ethanol-induced gastroulcer rat model to analyze the antiulcer and immunomodulatory activities of Phyllanthus reticulatus as this model resembles human acute gastric ulcer [26]. It is the most commonly used model to induce gastric ulcer because this method is rapid and is an easy way to evaluate antiulcer activity of plant extract or active ingredient [13]. Ethanol causes direct and indirect damage to the stomach. Direct injury is caused with rapid entry into stomach lining, resulting in vascular endothelial dysfunction. This effect is attributed to hypoxia, hemorrhagic necrosis, and reduction in gastric mucus secretion. As a result, the flow of $\mathrm{Na}^{+} / \mathrm{K}^{+}$and secretion of pepsin increases, and $\mathrm{H}^{+}$accumulates in the gastric cavity $[13,27]$. The indirect damage is ascribed to the recruitment of leukocytes that stimulates the inflammatory responses by increasing the levels of various proinflammatory cytokines [28]. A significant elevation in the total ulcer score, reduction in $\mathrm{pH}$ value, and rise in gastric acidity was determined in the ethanol only administered group. These changes of gastric mucosal inflammation are consistent with the studies previously performed $[29,30]$. Pretreatment with plant extracts significantly inhibited all these ethanol-induced gastric effects. These results are comparable with the inferences of previous studies [31, 32].

P. reticulatus extracts significantly reduced the severity of erosion score, hemorrhage score, fibrinoid necrosis score, inflammatory infiltrate score, edema score, and ulcer score. Rats that received pretreatment with $P$. reticulatus had comparatively better protection of the gastric mucosa as observed by marked reduction of different parameters. The research studies previously done showed that TNF- $\alpha$ and IL8 play an important role in causing gastric mucosal lesions as their levels are significantly increased in ethanol-induced stomach ulcer [33, 34].

Proinflammatory cytokine TNF- $\alpha$ has pleiotropic roles [35]. It plays crucial role in the formation of gastric ulcer by eliciting an acute inflammatory reaction accompanied by neutrophil infiltration in gastric mucosa [36]. It also 
TABLE 1: Histopathological scoring of gastric mucosa of rats.

\begin{tabular}{lcccccc}
\hline Groups & Erosion score & Ulcer score & Hemorrhage score & Fibrinoid score & Inflammatory infiltrate score & Edema score \\
\hline Naïve & 0 & 0 & 0 & 0 & 4 & 0 \\
Vehicle control & 5 & 5 & 2 & 4 & 4 & 2 \\
Meth-treated & 2 & 3 & 0 & 2 & 3 & 2 \\
NH-treated & 1 & 3 & 0 & 3 & 1 & 2 \\
EA-treated & 0 & 1 & 0 & 1 & 0 & 3 \\
OM-treated & 1 & 2 & & & & 2 \\
\hline
\end{tabular}

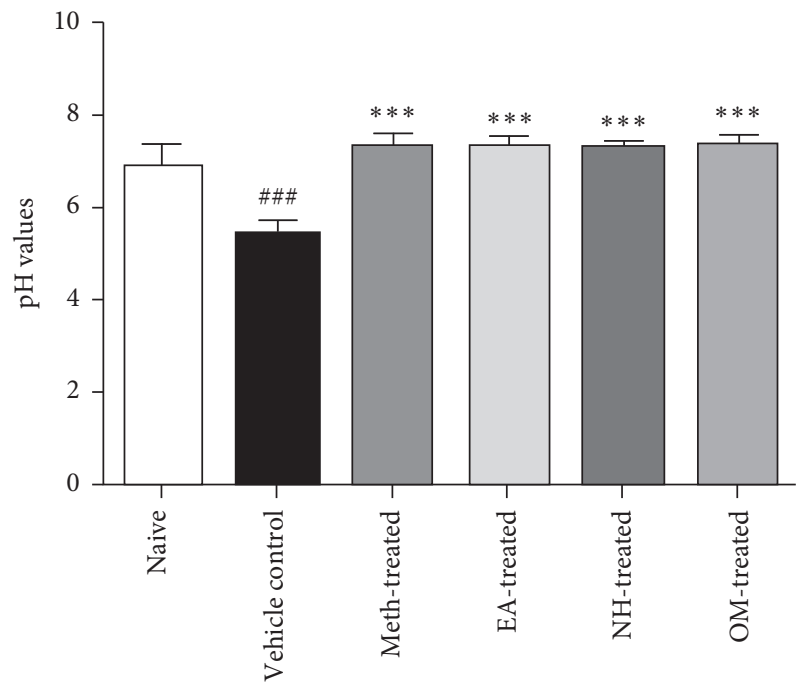

FIGURE 2: The $\mathrm{pH}$ values were found significantly increased in all treated groups compared to the vehicle control group $(P<0.001)$.

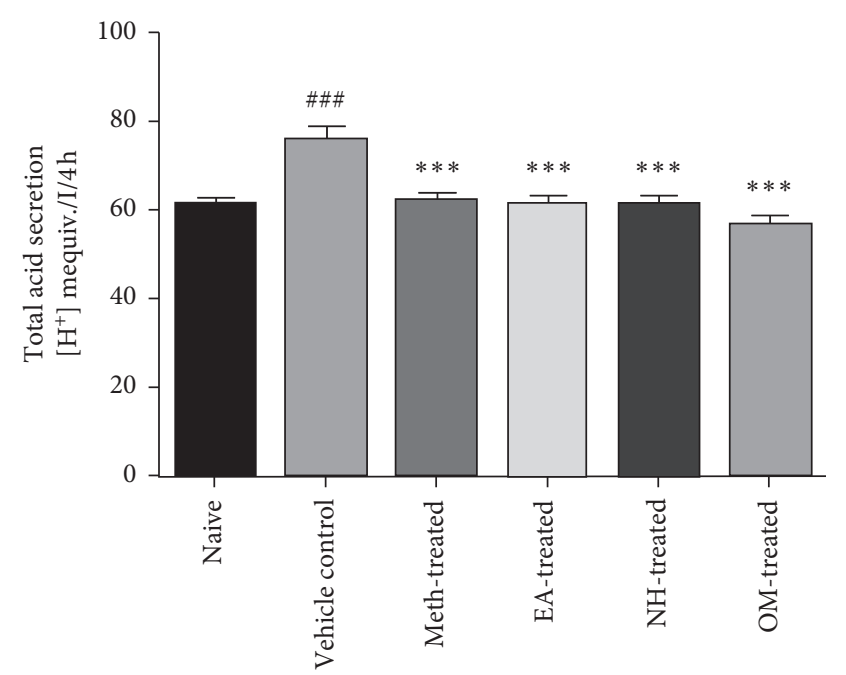

FIGURE 3: The total acid secretin was substantially decreased $(P<0.001)$ in all treated groups as compared to the vehicle control group.

regulates apoptotic cell death in the gastric mucosa [36, 37]. It is known to suppress gastric microcirculation, cell proliferation, and angiogenesis at the ulcer margin, thus delaying ulcer healing $[28,38]$. Therefore, it may be perceived that reduction in the TNF- $\alpha$ level might facilitate

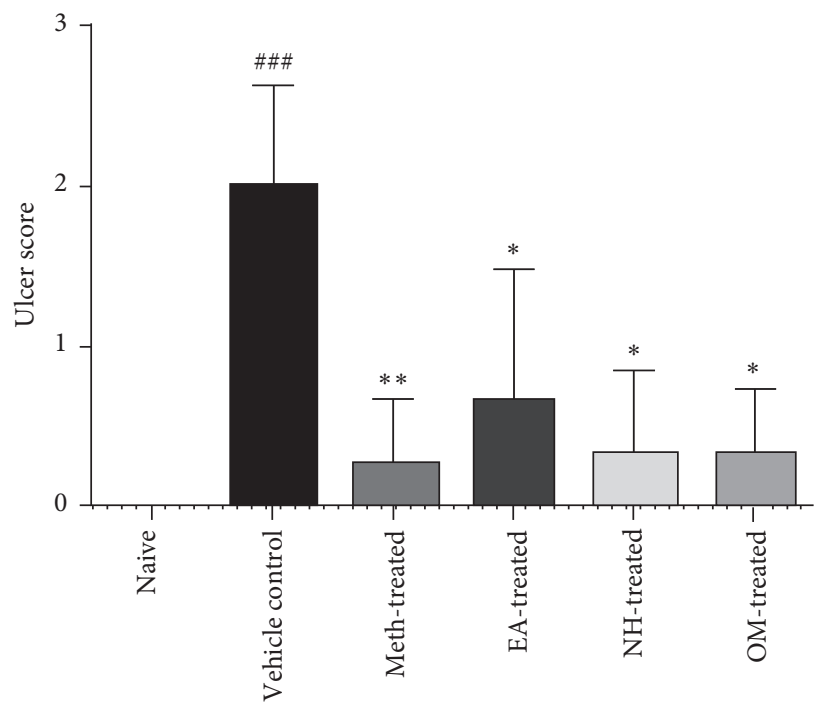

FIGURE 4: All treatment groups showed reduction in the ulcer score as compared to the vehicle control group. The data were analyzed using the Kruskal-Wallis test followed by Dunn's multiple comparison test.

ulcer healing. In this context, TNF- $\alpha$ expression levels were examined in our study, and results revealed elevated levels in the positive control group which were found significantly attenuated in $p$. reticulatus treated groups. Our findings are in line with the results of Du et al. and Jainu et al. [39, 40]. These studies suggested that the amelioration of stomach ulcer with Veronicastrum axillare and Cissus quadrangularis extracts was attributed to the reduction in the raised TNF- $\alpha$ levels.

IL-8 is an important chemotactic and activating factor for neutrophils. The secretion of IL- 8 by epithelial cells is probably a key factor in host defences at mucosal sites, permitting a rapid polymorph response against infectious agents. If defence mechanisms fail and chronic infection results, continued upregulation of IL- 8 and neutrophil activation could lead to mucosal damage and increased free radical formation. Mucosal IL-8 production and $H$. pylori infection are two important factors in the immune-pathogenesis of peptic ulcer disease and may also be of relevance to gastric carcinogenesis [41, 42]. IL-8 is a multifunctional inflammatory cytokine that is considered a major controller of acute and chronic-inflammation. Earlier studies revealed that mRNA expression levels of IL-8 were significantly increased in gastric stomach ulcer $[21,43]$. We determined the effects of extracts of $P$. reticulatus on mRNA expression 


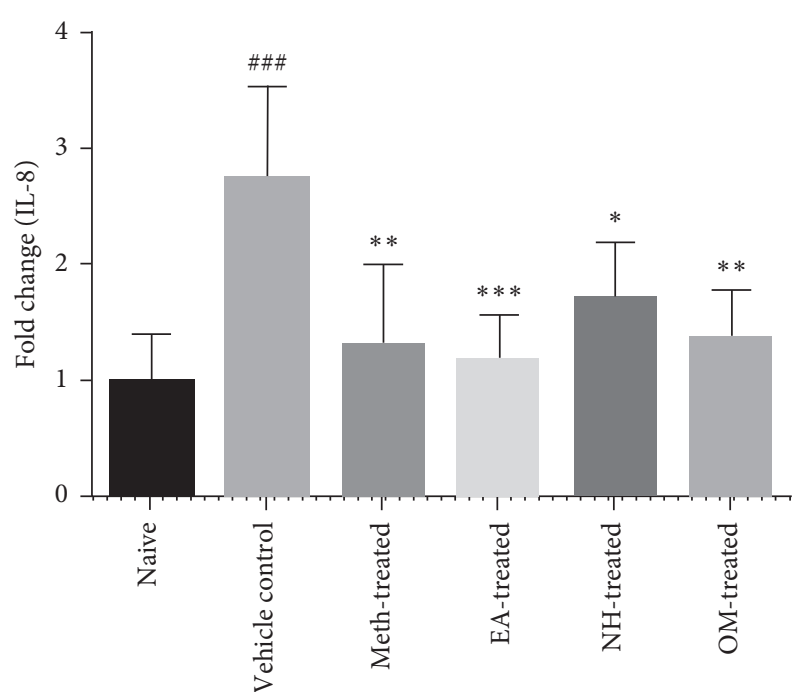

(a)

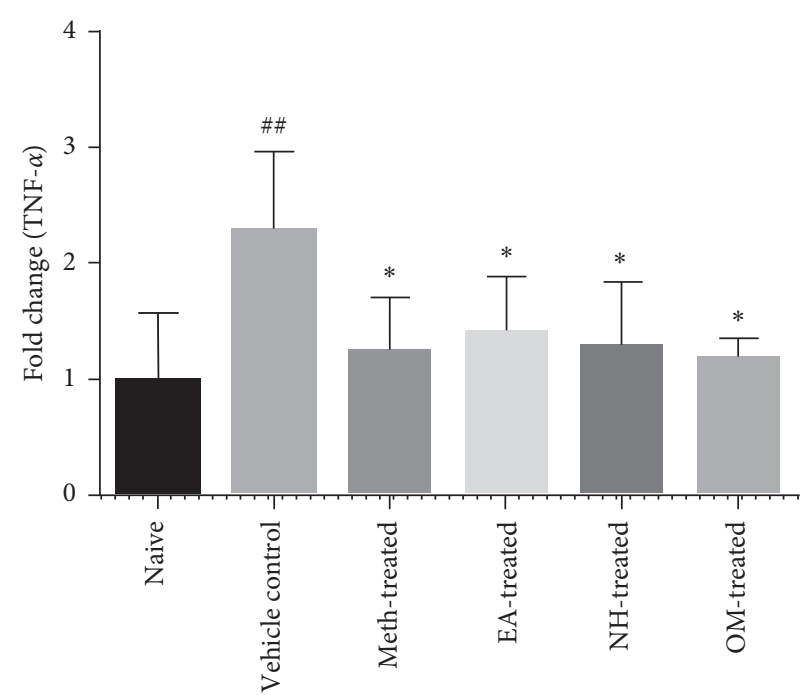

(b)

Figure 5: The data showing P. reticulatus significantly reduced the mRNA expression levels of IL-8 (a) and TNF- $\alpha$ (b) as compared to the vehicle control group.

levels of IL- 8 and found significant reduction in the treated groups as compared to the diseased group.

Our findings are in line with the results of earlier studies which attributed the gastroprotective effects against pylorus ligature-induced gastric ulcer in rats to reduce the raised IL8 levels [44].

\section{Conclusion}

Current research proposes that $P$. reticulatus possesses substantial antiulcer property which might be ascribed to anti-inflammatory and immunomodulatory activities. The data showed significant reduction in ulcer score, erosions, edema, hemorrhage, fibrinoid necrosis, inflammatory cell infiltration, and gastric acidity. These results might be attributed to downregulation of IL- 8 and TNF- $\alpha$ levels. To what extent, $P$. reticulatus clinically changed the intensity of inflammatory and immunomodulatory cytokines need more research studies.

\section{Data Availability}

The data used to support the findings of this study are available from the corresponding author upon request.

\section{Conflicts of Interest}

The authors declare that they have no conflicts of interest.

\section{Acknowledgments}

The authors wish to thank Dr. Adeem Rehman Raffie, Department of Pathology, University of Veterinary and Animal Sciences, Lahore, for his facilitation in histopathological evaluation.

\section{References}

[1] R. P. Mynatt, G. A. Davis, and F. Romanelli, "Peptic ulcer disease: clinically relevant causes and treatments," Orthopedics, vol. 32, no. 2, p. 104, 2009.

[2] A. S. Fauci, Harrison's Manual of Medicine, McGraw-Hill Medical, New York, NY, USA, 2009.

[3] V. Kumar, A. K. Abbas, N. Fausto, and J. C. Aster, Robbins and Cotran Pathologic Basis of Disease, Elsevier Saunders, Philadelphia, PA, USA, 2005.

[4] S. A. Mard, Z. Bahari, N. Eshaghi, and Y. Farbood, "Antiulcerogenic effect of Securigera securidaca L. seed extract on various experimental gastric ulcer models in rats," Pakistan Journal of Biological Sciences, vol. 11, no. 23, pp. 2619-2623, 2008.

[5] P. H. Canter, H. Thomas, and E. Ernst, "Bringing medicinal plants into cultivation: opportunities and challenges for biotechnology," Trends in Biotechnology, vol. 23, no. 4, pp. 180-185, 2005.

[6] V. Maruthappan and S. Shree, "A report on the antioxidant activity of the powder of the entire plant of Phyllanthus reticulatus Poir," International Journal of Green Pharmacy, vol. 4, no. 4, p. 265, 2010.

[7] M. S. Uddin, A. Mamun, M. A. Iqbal, A. Islam, M. F. Hossain, and S. Khanum, "Analyzing nootropic effect of Phyllanthus reticulatus Poir. on cognitive functions, brain antioxidant enzymes and acetylcholinesterase activity against aluminiuminduced Alzheimer's model in rats: applicable for controlling the risk factors of Alzheimer's disease," Advances in Alzheimer's Disease, vol. 5, no. 3, pp. 87-102, 2016.

[8] B. K. Das, S. Bepary, B. K. Datta, A. A. Chowdhury, M. S. Ali, and A. S. Rouf, "Hepatoprotective activity of Phyllanthus reticulatus," Pakistan Journal of Pharmaceutical Sciences, vol. 21, no. 4, pp. 333-337, 2008.

[9] B. Ijaz, A. Shabbir, M. Shahzad et al., "Amelioration of airway inflammation and pulmonary edema by Teucrium stocksianum via attenuation of pro-iinflammatory cytokines and up-regulation of AQP1 and AQP5," Respiratory Physiology \& Neurobiology, vol. 284, Article ID 103569, 2021. 
[10] M. Uroos, Z. Abbas, S. Sattar et al., "Nyctanthes arbor-tristis ameliorated FCA-induced experimental arthritis: a comparative study among different extracts," Evidence-based Complementary and Alternative Medicine, vol. 2017, Article ID 4634853, 2 pages, 2017.

[11] M. Abebaw, B. Mishra, and D. A. Gelayee, "Evaluation of antiulcer activity of the leaf extract of Osyris quadripartita Decne. (Santalaceae) in rats," Journal of Experimental Pharmacology, vol. 9, pp. 1-11, 2017.

[12] S. Kumar, S. Sharma, D. Kumar, T. Kumar, R. Arya, and K. Kumar, "Pharmacognostic study and anti - inflammatory activity of Phyllanthus reticulatus Poir. fruit," Asian Pacific Journal of Tropical Disease, vol. 2, pp. S332-S335, 2012.

[13] A. Mahmood, F. Al-Bayaty, I. Salmah, N. S. AB, and H. Harita, "Enhancement of gastric ulcer by Areca catechu nut in ethanol-induced gastric mucosal injuries in rats," Journal of Medicinal Plants Research, vol. 5, no. 12, pp. 2462-2469, 2011.

[14] G. S. Cerqueira, GdS. e Silva, E. R. Vasconcelos, A. P. F. de Freitas, B. A. Moura, and D. S. Macedo, "Effects of hecogenin and its possible mechanism of action on experimental models of gastric ulcer in mice," European Journal of Pharmacology, vol. 683, no. 1-3, pp. 260-269, 2012.

[15] B. Adhikary, S. K. Yadav, S. K. Bandyopadhyay, and S. Chattopadhyay, "Epigallocatechin gallate accelerates healing of indomethacin-induced stomach ulcers in mice," Pharmacological Reports, vol. 63, no. 2, pp. 527-536, 2011.

[16] H. G. Vogel and W. H. Vogel, "Analgesic, anti-inflammatory, and antipyretic activity," Drug Discovery and Evaluation, Springer, Berlin, Germany, pp. 360-420, 1997.

[17] W. Toma, C. A. Hiruma-Lima, R. O. Guerrero, and A. R. M. Souza Brito, "Preliminary studies of Mammea americana L. (Guttiferae) bark/latex extract point to an effective antiulcer effect on gastric ulcer models in mice," Phytomedicine, vol. 12, no. 5, pp. 345-350, 2005.

[18] R. Naz, Z. Ahmed, M. Shahzad, A. Shabbir, and F. Kamal, "Amelioration of rheumatoid arthritis by Anacardium occidentale via inhibition of collagenase and lysosomal enzymes," Evidence-based Complementary and Alternative Medicine, vol. 2020, Article ID 8869484, 11 pages, 2020.

[19] A. Mobashar, A. Shabbir, M. Shahzad, and H. Saeed-ul, "Evaluation of immunomodulatory and anti-arthritic potential of Trigonella gharuensis extracts," Evidence-based Complementary and Alternative Medicine, vol. 2020, Article ID 8836080, 7 pages, 2020.

[20] O. Olatunji, H. Chen, and Y. Zhou, "Anti-ulcerogenic properties of Lycium chinense mill extracts against ethanolinduced acute gastric lesion in animal models and its active constituents," Molecules, vol. 20, no. 12, pp. 22553-22564, 2015.

[21] S. Choi, S. Lee, Y. Kim, C. Ok, H. Lee, and K. Hahm, "Role of heat shock proteins in gastric inflammation and ulcer healing," Journal of Physiology \& Pharmacology, vol. 60, no. 7, pp. 5-17, 2009.

[22] M. P. d. Barros, M. Lemos, E. L. Maistro et al., "Evaluation of antiulcer activity of the main phenolic acids found in Brazilian Green Propolis," Journal of Ethnopharmacology, vol. 120, no. 3, pp. 372-377, 2008.

[23] L. Savegnago, M. Trevisan, D. Alves, J. B. T. Rocha, C. W. Nogueira, and G. Zeni, "Antisecretory and antiulcer effects of diphenyl diselenide," Environmental Toxicology and Pharmacology, vol. 21, no. 1, pp. 86-92, 2006.

[24] A. Bhattacharyya, R. Chattopadhyay, S. Mitra, and S. E. Crowe, "Oxidative stress: an essential factor in the pathogenesis of gastrointestinal mucosal diseases," Physiological Reviews, vol. 94, no. 2, pp. 329-354, 2014.

[25] M. S. Uddin, A. A. Mamun, M. A. Iqbal et al., "Analyzing nootropic effect of Phyllanthus reticulatus Poir. On cognitive functions, brain antioxidant enzymes and acetylcholinesterase activity against aluminium-induced alzheimer's model in rats: applicable for controlling the risk factors of alzheimer's disease," Advances in Alzheimer's Disease, vol. 05, no. 03, pp. 87-102, 2016.

[26] M. B. Adinortey, C. Ansah, I. Galyuon, and A. Nyarko, "In vivo models used for evaluation of potential antigastroduodenal ulcer agents," Ulcers, vol. 2013, Article ID 796405, 4 pages, 2013.

[27] S. Szabo, "Mechanisms of mucosal injury in the stomach and duodenum: time-sequence analysis of morphologic, functional, biochemical and histochemical studies," Scandinavian Journal of Gastroenterology, vol. 22, no. 27, pp. 21-28, 1987.

[28] H. H. Arab, S. A. Salama, H. A. Omar, E.-S. A. Arafa, and I. A. Maghrabi, "Diosmin protects against ethanol-induced gastric injury in rats: novel anti-ulcer actions," PloS One, vol. 10, no. 3, Article ID e0122417, 2015.

[29] J. L. Wallace, W. McKnight, B. K. Reuter, and N. Vergnolle, "NSAID-induced gastric damage in rats: requirement for inhibition of both cyclooxygenase 1 and 2," Gastroenterology, vol. 119, no. 3, pp. 706-714, 2000.

[30] A. Schmassmann, B. M. Peskar, C. Stettler et al., "Effects of inhibition of prostaglandin endoperoxide synthase-2 in chronic gastro-intestinal ulcer models in rats," British Journal of Pharmacology, vol. 123, no. 5, pp. 795-804, 1998.

[31] F. Nabavizadeh, A. M. Alizadeh, S. Adeli, M. Golestan, H. Moloudian, and M. Kamalinejad, "Gastroprotective effects of Stachys Lavandulifolia extract on experimental gastric ulcer," African Journal of Pharmacy and Pharmacology, vol. 5, no. 2, pp. 155-159, 2011.

[32] M. M. Khattab, M. Z. Gad, and D. Abdallah, "Protective role of nitric oxide in indomethacin-induced gastric ulceration by a mechanism independent of gastric acid secretion," Pharmacological Research, vol. 43, no. 5, pp. 463-467, 2001.

[33] J. Yao, "Tiao He Yi Wei granule, a traditional Chinese medicine, against ethanol-induced gastric ulcer in mice," Evidence-based Complementary and Alternative Medicine, vol. 2015, Article ID 647283, 8 pages, 2015.

[34] M. Sugimoto, T. Ohno, D. Y. Graham, and Y. Yamaoka, "Gastric mucosal interleukin-17 and -18 mRNA expression inHelicobacter pylori-induced Mongolian gerbils," Cancer Science, vol. 100, no. 11, pp. 2152-2159, 2009.

[35] S. Fiorucci, E. Antonelli, G. Migliorati et al., "TNF $\alpha$ processing enzyme inhibitors prevent aspirin-induced TNF $\alpha$ release and protect against gastric mucosal injury in rats," Alimentary Pharmacology \& Therapeutics, vol. 12, no. 11, pp. 1139-1153, 1998.

[36] S. A. Hussein, M. M. Karousa, A. Amin, and M. A. Awadalla, "Evaluation of gastroprotective effect and anti-inflammatory role of resveratrol against gastric mucosal alterations in experimental model of gastritis in rats," Digestive System Diseases, vol. 8, 2016.

[37] S. B. Almasaudi, N. A. El-Shitany, A. T. Abbas, U. A. Abdeldayem, S. S. Ali, and S. K. Al Jaouni, "Antioxidant, anti-inflammatory, and antiulcer potential of manuka honey against gastric ulcer in rats," Oxidative Medicine and Cellular Longevity, vol. 2016, Article ID 3643824, 10 pages, 2016.

[38] L. Moezi, R. Heidari, Z. Amirghofran, A. A. Nekooeian, A. Monabati, and A. R. Dehpour, "Enhanced anti-ulcer effect of pioglitazone on gastric ulcers in cirrhotic rats: the role of 
nitric oxide and IL-1 $\beta$," Pharmacological Reports, vol. 65, no. 1, pp. 134-143, 2013.

[39] Y. Du, W. Zhao, L. Lu et al., "Study on the antiulcer effects of Veronicastrum axillare on gastric ulcer in rats induced by ethanol based on tumor necrosis factor- $\alpha$ (TNF- $\alpha$ ) and endothelin-1 (ET-1)," Asian Pacific journal of tropical biomedicine, vol. 3, no. 12, pp. 925-930, 2013.

[40] M. Jainu and C. S. S. Devi, "Gastroprotective action of Cissus quadrangularis extract against NSAID induced gastric ulcer: role of proinflammatory cytokines and oxidative damage," Chemico-Biological Interactions, vol. 161, no. 3, pp. 262-270, 2006.

[41] J. E. Crabtree and I. Lindley, "Mucosal interleukin-8 and Helicobacter pylori-associated gastroduodenal disease," European Journal of Gastroenterology \& Hepatology, vol. 6, pp. S33-S38, 1994.

[42] Z. Gyulai, G. Klausz, A. Tiszai et al., "Genetic polymorphism of interleukin-8 (IL-8) is associated with Helicobacter pyloriinduced duodenal ulcer," European Cytokine Network, vol. 15, no. 4, pp. 353-358, 2004.

[43] L. L. Eftang, Y. Esbensen, T. M. Tannæs, I. R. Bukholm, and G. Bukholm, "Interleukin- 8 is the single most up-regulated gene in whole genome profiling of $H$. pylori exposed gastric epithelial cells," BMC Microbiology, vol. 12, no. 1, p. 9, 2012.

[44] X. Mei, X. Luo, S. Xu et al., "Gastroprotective effects of a new zinc(II)-curcumin complex against pylorus-ligature-induced gastric ulcer in rats," Chemico-Biological Interactions, vol. 181, no. 3, pp. 316-321, 2009. 